None declared, Alexander Kreuter: None declared, Georg Schett Speakers bureau: AbbVie, BMS, Celgene, Janssen, Eli Lilly, Novartis, Roche and UCB, Jörg Distler Grant/research support from: Boehringer Ingelheim, Consultant of: Boehringer Ingelheim, Paid instructor for: Boehringer Ingelheim, Speakers bureau: Boehringer Ingelheim, Andreas Ramming Grant/research support from: Pfizer, Novartis, Consultant of: Boehringer Ingelheim, Novartis, Gilead, Pfizer, Speakers bureau: Boehringer Ingelheim, Roche, Janssen DOI: 10.1136/annrheumdis-2020-eular.5745

\section{OP0142 FIBROBLAST GROWTH FACTOR RECEPTOR 3 REGULATES THE ACTIVITY OF PROFIBROTIC CYTOKINE AND GROWTH FACTOR PATHWAYS TO DRIVE FIBROBLAST ACTIVATION AND TISSUE FIBROSIS IN SYSTEMIC SCLEROSIS}

D. Chakraborty ${ }^{1}$, H. Zhu ${ }^{2,3}$, A. Juengel ${ }^{4}$, L. Summa ${ }^{2}$, Y. N. LI ${ }^{2}$, C. Bergmann ${ }^{2}$, A. E. Matei ${ }^{2}$, T. Trinh-Minh ${ }^{2}$, C. W. Chen ${ }^{2}$, C. Dees ${ }^{2}$, A. Ramming ${ }^{2}$, G. Schett ${ }^{2}$ O. Distler ${ }^{4}$, J. Distler ${ }^{2}{ }^{1}$ Friedrich-Alexander University (FAU) ErlangenNürnberg and Universitätsklinikum Erlangen, 1Department of Internal Medicine 3 - Rheumatology and Immunology, Erlangen, Germany; ${ }^{2}$ FriedrichAlexander University (FAU) Erlangen-Nürnberg and Universitätsklinikum Erlangen, Department of Internal Medicine 3 - Rheumatology and Immunology, Erlangen, Germany; ${ }^{3}$ Xiangya Hospital, Central South University, Department of Rheumatology, Changsha, Hunan, China; ${ }^{4}$ University of Zurich, Zürich, Switzerland

Background: Fibroblast growth factor receptor 3 (FGFR3) is a member of the family of different fibroblast growth factor receptors with several ligands called fibroblast growth factors (FGFs) in humans. Each FGFR has different isoforms resulting from natural alternative splice variants. Upon binding FGF ligands, fibroblast growth factor receptors (FGFRs) trigger various intracellular signaling pathways to regulate important biological processes. Systematic evaluation of FGF/FGFR signaling in the context of SSc has not been performed so far.

Objectives: The aim of this study was to characterize FGFR3/FGF9 signaling in the context of fibroblast activation and to evaluate FGFR3 as a potential molecular target for antifibrotic treatment in SSc.

Methods: Differential expression profiling of dermal cells from SSc patients and healthy volunteers were performed employing GEArray CDNA microarray. Realtime PCR, Western Blot, immunohistochemistry and immunofluorescence were done in skin tissues and fibroblasts from SSc patients. Selective inhibitors in conjunction with genetic knockdown and knockout strategies were used to target FGFR3 signaling in vitro and in mouse models of SSc: skin fibrosis induced by bleomycin and by overexpression of a constitutively active transforming growth factor receptor 1 (TBR) and tight skin-1 (TSK) mice. Affymetrix gene arrays in dermal fibroblasts from mice with constitutive FGFR3 signaling and mice lacking FGFR3.

Results: Expression of FGFR3, specifically the isoform FGFR3Illb and its ligand FGF9, was significantly upregulated in the dermis and dermal fibroblasts of SSc patients as compared to healthy volunteers. Furthermore, an increase of FGFR3 IIlb/FGF9 expression comparable to that in SSc fibroblasts could also be obtained by stimulating normal healthy dermal fibroblasts with transforming growth factor (TGF $\beta$ ) in vitro and in mice constitutively overexpressing active TGF $\beta$ receptor type I.

Transcriptome profiling, in silico analysis and functional experiments revealed that FGFR3 synergistigically induces multiple profibrotic pathways including Endothelin-, Interleukin-4- and CTGF-signaling in a CREB-dependent manner. FGFR3 exerts profibrotic effects by modulating phosphorylation of CREB by ERK-, AKT-, CAMK2- and p38-kinases. Activation of FGFR3 in healthy or SSc dermal fibroblasts by stimulation with recombinant FGF9 was sufficient to induce resting fibroblast-to-myofibroblast differentiation along with increased collagen secretion and alpha-SMA production.

Genetic knockout of Fgfr3 abrogates myofibroblast differentiation in vitro and ameliorates skin fibrosis in TSK and TBR mice and in bleomycin-induced fibrosis. Further confirming the translational potential of these findings in the preclinical models of SSc, we demonstrate that pharmacological inactivation of FGFR3 by PD173074 could induce the regression of experimental fibrosis in vitro and in bleomycin-challenged, TSK and TBR mice.

Conclusion: Our findings characterize FGFR3 as an upstream regulator of a network of profibrotic mediators in SSc and thus, we could demonstrate successfully that the targeted inhibition of FGFR3 could inhibit multiple signaling pathways in vitro and ameliorated fibrosis in different preclinical models of SSc. These findings may have direct translational implications as FGFR3 inhibitors are currently in development.

Disclosure of Interests: Debomita Chakraborty: None declared, Honglin Zhu: None declared, Astrid Juengel: None declared, Lena Summa: None declared,
Yi-Nan Li: None declared, Christina Bergmann: None declared, Alexandru-Emil Matei: None declared, Thuong Trinh-Minh: None declared, Chih-Wei Chen: None declared, Clara Dees: None declared, Andreas Ramming: None declared, Georg Schett Speakers bureau: AbbVie, BMS, Celgene, Janssen, Eli Lilly, Novartis, Roche and UCB, Oliver Distler Grant/research support from: Grants/Research support from Actelion, Bayer, Boehringer Ingelheim, Competitive Drug Development International Ltd. and Mitsubishi Tanabe; he also holds the issued Patent on mir-29 for the treatment of systemic sclerosis (US8247389, EP2331143)., Consultant of: Consultancy fees from Actelion, Acceleron Pharma, AnaMar, Bayer, Baecon Discovery, Blade Therapeutics, Boehringer, CSL Behring, Catenion, ChemomAb, Curzion Pharmaceuticals, Ergonex, Galapagos NV, GSK, Glenmark Pharmaceuticals, Inventiva, Italfarmaco, iQvia, medac, Medscape, Mitsubishi Tanabe Pharma, MSD, Roche, Sanofi and UCB, Speakers bureau: Speaker fees from Actelion, Bayer, Boehringer Ingelheim, Medscape, Pfizer and Roche, Jörg Distler Grant/research support from: Boehringer Ingelheim, Consultant of: Boehringer Ingelheim, Paid instructor for: Boehringer Ingelheim, Speakers bureau: Boehringer Ingelheim DOI: 10.1136/annrheumdis-2020-eular.2915

\section{Vasculitis}

\section{$\mathrm{OP} 0143$ \\ CANCER IN GIANT-CELL ARTERITIS PATIENTS: A LARGE NATIONWIDE STUDY}

N. Ben-Shabat ${ }^{1}$, L. Dar ${ }^{2,3}$, S. Tiosano ${ }^{2,3}$, A. Watad ${ }^{1,2,3}$, D. Comanesther ${ }^{4}$, A. Cohen ${ }^{4}$, H. Amital ${ }^{1,2,3} .{ }^{1}$ Tel-Aviv University, Sackler Faculty of Medicine, Tel-Aviv, Israel; ${ }^{2}$ Sheba Medical Center, Medicine B, Ramat-Gan, Israel; ${ }^{3}$ Sheba Medical Center, The Zabludowicz Center for Autoimmune Diseases, RamatGan, Israel; ${ }^{4} \mathrm{Clalit}$ Health Services, Chief Physician's Office, Tel-Aviv, Israel

Background: The association between giant-cell arteritis (GCA) and malignancy is controversial.

Objectives: To asses malignancy rates and risk in GCA patients in a large-scale population-based study.

Methods: We utilized the medical database of Clalit-Health-Services for this retrospective cohort study. Follow-up was from January 1,2002 and continued until death or end of follow-up on September 1,2018. Incident GCA patients were compared with age-and-sex-matched controls. Hazard-ratios for subtypes of malignancies were obtained by the Cox proportional-hazard model, adjusted for socio-demographic variables and cancer risk factors.

Results: The study population included 7,213 GCA patients and 32,987 ageand sex-matched controls who were not diagnosed with the disease. The mean age of GCA diagnosis was $72.3 \pm 9.9$ years (median 73.1 years) and $69.1 \%$ were women. At Kaplan-Meier survival analysis, assessing cumulative cancer-free survival in GCA patients and controls, GCA patients had worse curve than controls (chi-squared $=49.84$; degrees of freedom $=1 ; p<0.0001$; Figure 1 ). At the cox-survival analysis adjusted for age, sex, SES and cancer risk factors GCA patients showed increased risk for overall cancer (HR 1.29 [95\%Cl 1.20-1.39]),

Table 1. Cox survival analysis assessing crude and adjusted hazard for cancer in GCA patients compare to controls

\begin{tabular}{lcc}
\hline \multicolumn{1}{c}{ Type of malignancy } & \multicolumn{2}{c}{ Adjusted HR } \\
\cline { 2 - 3 } & $\mathrm{HR}$ & 95\% Cl \\
\hline Any malignancy & 1.29 & $1.20,1.39$ \\
Oropharyngeal cancer & 0.96 & $0.69,1.35$ \\
Thyroid cancer & 1.20 & $0.66,2.16$ \\
Breast cancer & 0.93 & $0.75,1.14$ \\
Lung cancer & 1.26 & $0.99,1.59$ \\
Esophagus cancer & 1.86 & $0.93,3.75$ \\
Stomach Cancer & 0.61 & $0.37,0.98$ \\
Colorectal Cancer & 1.12 & $0.93,1.36$ \\
Liver and bile ducts cancer & 1.06 & $0.69,1.62$ \\
Kidney cancer & 1.60 & $1.15,2.23$ \\
Bladder cancer & 1.15 & $0.88,1.50$ \\
Uterus cancer & 0.85 & $0.55,1.30$ \\
Cervical cancer of the uterus & 0.45 & $0.37,1.46$ \\
Ovary Cancer & 0.96 & $0.58,1.59$ \\
Prostate Cancer & 1.07 & $0.80,1.43$ \\
Sarcoma & 2.14 & $1.41,3.24$ \\
Melanoma & 1.11 & $0.80,1.55$ \\
Acute Leukemia & 1.81 & $1.06,3.07$ \\
Chronic Leukemia & 1.82 & $1.19,2.77$ \\
Myelodysplastic syndrome & 1.84 & $0.94,3.60$ \\
Hodgkin's Lymphoma & 2.42 & $1.12,5.20$ \\
Non-Hodgkin's Lymphoma & 1.66 & $1.21,2.29$ \\
Multiple Myeloma & 2.40 & $1.63,3.53$ \\
\hline
\end{tabular}

